\title{
Analysis of Phenolic Compounds in Rhubarbs Using Liquid Chromatography Coupled with Electrospray Ionization Mass Spectrometry
}

\author{
Min Ye, Jian Han, Hubiao Chen, Junhua Zheng, and Dean Guo \\ The State Key Laboratory of Natural and Biomimetic Drugs, School of Pharmaceutical Sciences, Peking \\ University, Beijing, People's Republic of China
}

Rhubarb is an important herbal medicine for the treatment of constipation, inflammation, and cancer. In this study, a facile method based on liquid chromatography coupled with electrospray ionization tandem mass spectrometry has been established for the analysis of bioactive phenolic compounds in rhubarbs. From six rhubarb species, official (Rheum officinale, R. palmatum, and R. tanguticum) and unofficial (R. franzenbachii, R. hotaoense, and R. emodi), a total of 107 phenolic compounds were identified or tentatively characterized based on their mass spectra. These compounds include sennosides, anthraquinones, stilbenes, glucose gallates, naphthalenes, and catechins. Ion chromatograms for the identified compounds of different rhubarbs were then compared. Consistent with previous reports, sennosides and rhein were only detected in official rhubarbs. Unexpectedly, we found that $R$. officinale contained very different phenolic compounds from the other two official species. Sennoside A, which has been considered as the major purgative component of rhubarb, was only detected in R. officinale, while its close isomers were observed in R. palmatum and R. tanguticum. In addition, the predominant anthraquinone glycosides in $R$. officinale were found to be rhein 8-O-glucoside and emodin 1-O-glucoside, whereas those in R. palmatum and $\mathrm{R}$. tanguticum were rhein 1-O-glucoside and emodin 8-O-glucoside. Stilbenes, which are the major constituents of unofficial rhubarbs, were also different among the species. Our results clarify the chemical composition of rhubarbs comprehensively for the first time. Due to the significant differences in chemical components of rhubarbs, we suggest that different Rheum species be used separately in clinical practice. (J Am Soc Mass Spectrom 2007, 18, 82-91) (C) 2007 American Society for Mass Spectrometry

$\mathrm{R}$ hubarb is one of the most well-known and frequently used herbal medicines for the treatment of constipation, inflammation, and cancer $[1,2]$. As described in the Chinese Pharmacopoeia, rhubarb consists of the roots and rhizomes of Rheum officinale Baill., R. palmatum L., and R. tanguticum Maxim. ex Balf., all of which belong to Sect. Palmata [3]. The major bioactive constituents of rhubarb are phenolic compounds. Among them, sennosides (bianthrones) and anthraquinone glycosides are considered as the main purgative components, while free anthraquinones possess anti-inflammatory effects [1]. In addition, glucose gallates [4,5], naphthalenes [6], and catechins [7] are isolated from rhubarbs, and exhibit potent antioxidant and anticancer activities. Aside from Sect. Palmata, species from Sect. Rheum are also used for rhubarb drugs in local areas of China. These unofficial

Published online October 6, 2006

Address reprint requests to Professor D. Guo, The State Key Laboratory of Natural and Biomimetic Drugs, School of Pharmaceutical Sciences, Peking University, 38 Xueyuan Road, Beijing 100083, People's Republic of China. E-mail: gda@bjmu.edu.cn, also Min Ye at min.ye@yale.edu

Current address: Department of Pharmacology, Yale University School of Medicine, New Haven, CT 06520, USA. species include $R$. franzenbachii Munt., $R$. hotaoense C.Y. Cheng et C.T. Kao, and R. emodi Wall. They exhibit much weaker purgative activities than official species due to the absence of sennosides and due to the relatively low content of anthraquinones [1]. The unofficial rhubarbs do contain high amounts of stilbenes, however. Stilbenes can lower sugar and lipid levels in human blood, and can be used to treat hyperlipidemia, obesity, and diabetes [8]. Antitumor activities of stilbenes have also been reported $[9,10]$.

Although official and unofficial rhubarbs show significant difference in purgative effects, they are similar in physical appearance and are difficult to distinguish by conventional means. Therefore, a simple, rapid, and accurate method for the analysis of bioactive compounds in rhubarb is necessary for the quality control of crude rhubarb drugs and their pharmaceutical preparations. Qualitative and quantitative analyses of rhubarbs have been extensively pursued [11-14]. However, most of these investigations focus on the determination of anthraquinones by TLC, HPLC, and HPCE. Simultaneous analysis of various types of compounds, as well as the comparison of different rhubarb species, has rarely been addressed. As a matter of fact, the current knowledge on chemistry of 
rhubarbs derives mostly from the results of Xiao et al. in 1984 [1]. However, chemical analysis in that research was conducted by thin-layer chromatography, which suffers from low sensitivity and poor resolution. Thus, the overall chemical composition of rhubarbs and the precise difference of various species remain unclear, so far.

Liquid chromatography coupled with mass spectrometry (LC/MS) is a powerful technique for the analysis of complex botanical extracts $[15,16]$. HPLC is efficient in separating chemical compounds in a mixture, and MS provides abundant information for structural elucidation of the compounds when tandem mass spectrometry $\left(\mathrm{MS}^{\mathrm{n}}\right)$ is applied. Therefore, the combination of HPLC and MS facilitates rapid and accurate identification of chemical compounds in medicinal herbs, especially when a pure standard is unavailable. Recently, LC/MS has been extensively used for the analysis of phenolic compounds [1722]. Electrospray ionization ${ }^{\circ}(\mathrm{ESI}){ }^{\circ}$ is $^{\circ} \mathrm{a}^{\circ}$ preferred $^{\circ}$ source $^{\circ} \mathrm{due}$ to its high ionization efficiency for phenolic compounds. However, few efforts are devoted to anthraquinones, which are ubiquitously present in plants and show important bioactivities.

We report here the comprehensive analysis of phenolic compounds in six rhubarb species (including official and unofficial) using a newly established HPLC/ESI-MS ${ }^{n}$ method (Figure S-1, which can be found in the electronic version of the article). A total of 107 compounds, including 20 anthraquinones, 28 sennosides, 34 stilbenes, 19 glucose gallates, 3 naphthalenes, and 3 catechins were identified. Most of them are reported for the first time. By comparing chemical profiles of the species, we found that the studied official and unofficial rhubarbs contained different chemical components. Based on our results, the validity that different Rheum species serve as the same drug needs to be reevaluated.

\section{Experimental}

\section{Chemicals}

Chrysophanol, emodin, aloe-emodin, physcion, and rhein were purchased from China Institute for Control of Pharmaceutical and Biological Products (Beijing, China). Chrysophanol 8-O- $\beta$-D-glucoside, emodin 8-O$\beta$-D-glucoside, rhein $8-O-\beta$-D-glucoside, and sennoside A were isolated from rhubarb. Their purities were above $95 \%$, as determined by HPLC analysis. HPLC grade acetonitrile (Fisher, Fair Lawn, NJ) and ultra-pure water were used for all analyses. AR grade methanol and acetic acid $\left(\mathrm{CH}_{3} \mathrm{COOH}\right)$ were purchased from Beijing Chemical Corporation (Beijing, China).

\section{Sample Preparation}

Rhubarb roots were collected and authenticated by the authors between 1994-1996 in Sichuan, Shanxi, and Shaanxi provinces, China. The plant materials were air-dried and stored at room temperature in an air-tight container. For LC/MS analysis, the samples were ground into fine powder (100-150 mesh). An aliquot of $0.25 \mathrm{~g}$ was weighed, and extracted with $10 \mathrm{ml}$ of methanol in an ultrasonic water bath at $25^{\circ} \mathrm{C}$ for 30 min. The solution was filtered through $0.2-\mu \mathrm{m}$ membranes before use, and a 5- $\mu$ l aliquot was injected into HPLC for analysis.

\section{Chromatography}

The analyses were performed on an Agilent series 1100 HPLC instrument (Agilent, Waldbronn, Germany) equipped with a quaternary pump, a diode-array detector (DAD), an autosampler, and a column compartment. The sample was separated on a Zorbax Eclipse $\mathrm{XDB} \mathrm{C}_{18}$ column $(5 \mu \mathrm{m}, 4.6 \times 250 \mathrm{~mm}$, Agilent). The mobile phase consisted of acetonitrile $\left(\mathrm{CH}_{3} \mathrm{CN}\right)$ and water containing $0.5 \%$ (vol/vol) $\mathrm{CH}_{3} \mathrm{COOH}$, with a gradient from 18 to $34 \% \mathrm{CH}_{3} \mathrm{CN}$ over the first $20 \mathrm{~min}$, then to $80 \%$ in $8 \mathrm{~min}$, and held at $80 \% \mathrm{CH}_{3} \mathrm{CN}$ for another $12 \mathrm{~min}$. The flow rate was $0.8 \mathrm{ml} / \mathrm{min}$, and column temperature was set at $30^{\circ} \mathrm{C}$. The DAD detector was monitored at $360 \mathrm{~nm}$, and the on-line UV spectra were recorded in the range 190-400 $\mathrm{nm}$.

\section{Mass Spectrometry}

A Finnigan LCQ Advantage ion trap mass spectrometer (ThermoFinnigan, San Jose, CA) was connected to the Agilent 1100 HPLC instrument via an ESI interface. The LC effluent was introduced into the ESI source in a post-column splitting ratio of 2:1. Ultrahigh-purity helium $(\mathrm{He})$ was used as the collision gas and high-purity nitrogen $\left(\mathrm{N}_{2}\right)$ as the nebulizing gas. The MS detector was optimized by injecting a $5-\mu \mathrm{l} / \mathrm{min}$ flow of anthraquinone standards $(0.1 \mathrm{mg} / \mathrm{ml}$ in methanol $)$ to obtain maximum intensities of $[\mathrm{M}-\mathrm{H}]^{-}$ions. The optimized parameters in the negative ion mode were as follows: ion spray voltage, $4.5 \mathrm{kV}$; sheath gas $\left(\mathrm{N}_{2}\right), 60$ arbitrary units; auxiliary gas $\left(\mathrm{N}_{2}\right), 15$ units; capillary temperature, $34{ }^{\circ} \mathrm{C}$; capillary voltage, $-20 \mathrm{~V}$; tube lens offset voltage, $-10 \mathrm{~V}$. For full scan MS analysis, the spectra were recorded in the range $m / z 120-1000$. A data-dependent acquisition was set so that the two most abundant ions in full scan MS would trigger tandem mass spectrometry $\left(\mathrm{MS}^{\mathrm{n}}, n=2-4\right)$. The collision energy for $\mathrm{MS}^{\mathrm{n}}$ was adjusted to $45 \%$ in LC/MS analysis, and the isolation width of precursor ions was 3.0 mass units.

\section{Results and Discussion}

\section{ESI-MS ${ }^{n}$ Analysis of Sennoside A}

In the negative ion mode, sennoside A gave a significant $[\mathrm{M}-\mathrm{H}]^{-}$ion at $m / z 861$, which was subjected to tandem mass spectrometry with collision energies varying from 35 to $45 \%$. The MS/MS spectrum gave $m / z 699$ as the base peak, resulting from the loss of glucose $(\Delta \mathrm{m}$ $={ }^{\circ} 162 \mathrm{u}^{\circ}{ }^{\circ}$ Figure $\left.^{\circ} 1 \mathrm{a}\right) .{ }^{\circ}$ Elimination ${ }^{\circ}$ of $^{\circ}$ the $^{\circ}$ second $^{\circ}$ glucosyl 

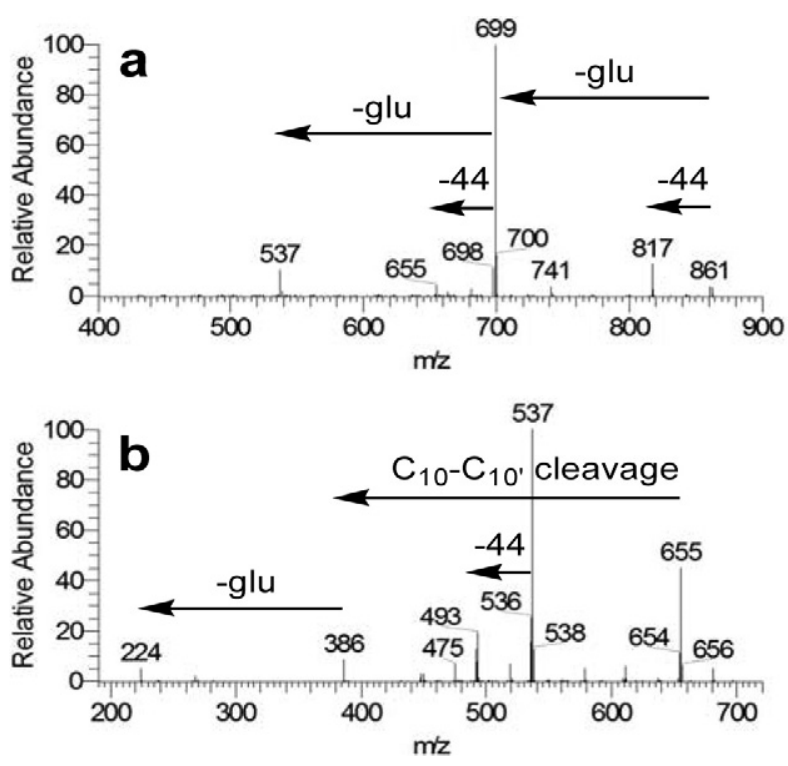

Figure 1. Full scan tandem mass spectra for sennoside A. (a) MS ${ }^{2}$ spectrum of the $[\mathrm{M}-\mathrm{H}]^{-}$ion at $\mathrm{m} / \mathrm{z} 861 ;(\mathbf{b}) \mathrm{MS}^{3}$ spectrum of the ion at $m / z$ 699. Glu, glucosyl residue. residue yielded the ion $m / z 537$. The $m / z 741$ ion in the MS/MS spectrum should come from ${ }^{0,2} \mathrm{X}$ cleavage of glucose, which is normally seen for phenoic glycosides [23]. In addition, significant ${ }^{\circ}$ neutral $10 s^{\circ}$ of 94 mass units $(\mathrm{m} / \mathrm{z} 861 \rightarrow 817$ and $\mathrm{m} / \mathrm{z} 699 \rightarrow 655)$ was observed, due to the elimination of a carboxyl group. In the $\mathrm{MS}^{3}$ spectrum of $\mathrm{m} / \mathrm{z} 699$, the ion at $\mathrm{m} / \mathrm{z} 386$ was noteworthy (Figure $\left.{ }^{\circ} 1 \mathrm{~b}\right) .^{\circ} \mathrm{We}^{\circ}$ assume ${ }^{\circ}$ that ${ }^{\circ}{ }^{\circ}{ }^{\circ}$ may $^{\circ}$ originate ${ }^{\circ}$ from ${ }^{\circ}$ the cleavage of $\mathrm{C}_{10}-\mathrm{C}_{10}$, bond (Scheme 1). Similar fragmentation was observed in the $\mathrm{MS}^{4}$ spectrum of $\mathrm{m} / \mathrm{z} 537$ $(537 \rightarrow 268)$. Based on the above spectral evidences, we proposed an MS fragmentation pathway for sennoside $\mathrm{A}$, as depicted in Scheme 1. The characteristic $\mathrm{C}_{10}-\mathrm{C}_{10^{\prime}}$ cleavage was used for rapid identification of sennosides in this study.

\section{Identification of Sennosides in Rhubarbs}

Although only six sennosides have been reported from Rheum species ${ }^{\circ}\left(\text { sennosides }^{\circ} \mathrm{A}-\mathrm{F}\right)^{\circ} \mathrm{So}^{\circ}$ far $^{\circ}[24]^{\circ},{ }^{\circ}{ }^{\circ}$ total ${ }^{\circ}$ of ${ }^{\circ} 28$ analogs (S1-S28) were identified in this study by LC/MS from Sect. Palmata species, i.e., R. officinale, R. palmatum, and $R$. tanguticum. Their structures and MS data are given in Table S-1. However, no sennoside was detected from

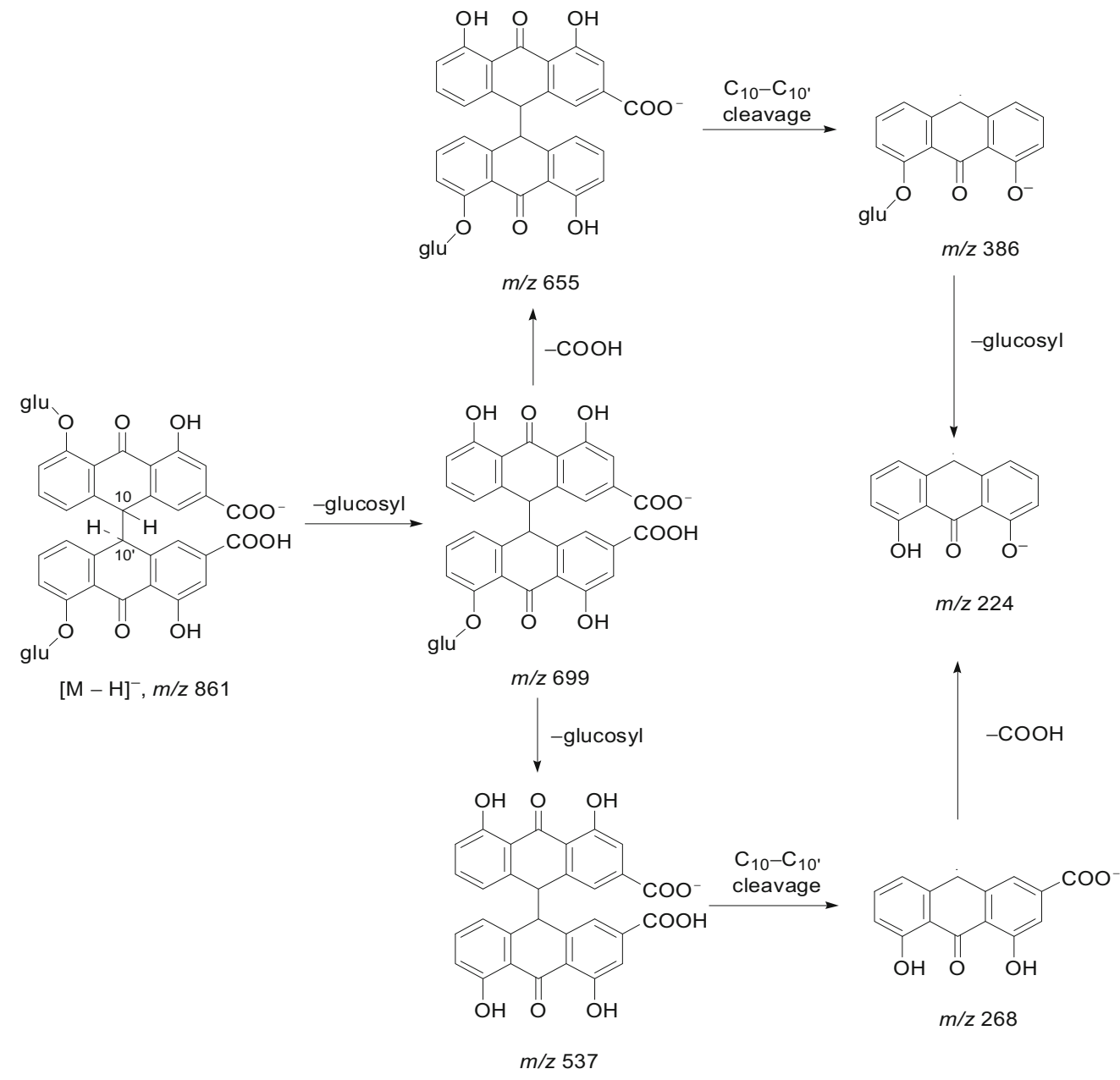

Scheme 1. Proposed MS fragmentation pathway for the $[\mathrm{M}-\mathrm{H}]^{-}$ion of sennoside A. 


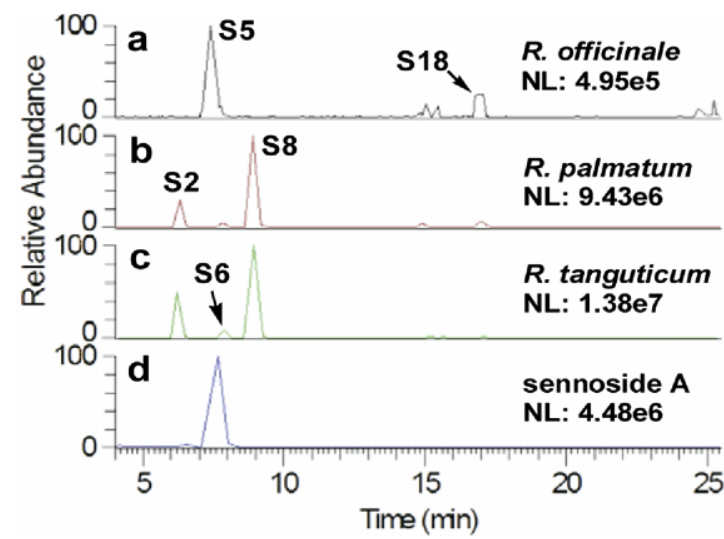

Figure 2. Extracted ion chromatograms (XIC) of $m / z 861$ for (a) Rheum officinale, (b) R. palmatum, (c) R. tanguticum, and (d) sennoside A. The peaks labeling coincide with Table S-1.

Sect. Rheum. This result is consistent with the previous report by Xiao et al., and indicated the taxonomic significance ${ }^{\circ}$ of $^{\circ}$ sennosides ${ }^{\circ}$ for ${ }^{\circ}$ Rheum species ${ }^{\circ}[1]$.

Unexpectedly, we found that sennosides of the three official rhubarbs were remarkably different from each other. Sennoside A (MW = 862) has been considered to be the major bianthrone in all official rhubarbs. However, at least five isomers of sennoside A were detected by LC/MS in our study, and different species gave different extracted ion chromatograms (XIC) for $m / z 861$ (Figure $\left.^{\circ} 2\right) .{ }^{\circ} \mathrm{Only}^{\circ} \mathrm{R}$. officinale showed ${ }^{\circ} \mathrm{a}^{\circ}$ peak $^{\circ}(\mathrm{S} 5)^{\circ}$ with identical retention time to sennoside $\mathrm{A}$ at $7.39 \mathrm{~min}$, while two significant peaks at $6.22 \mathrm{~min}$ (S2) and 8.94 min (S8) were observed in R. palmatum and R. tanguticum. A minor peak (S6) at 7.80 min was also detected in the latter two species. The difference in its retention time with sennoside $\mathrm{A}\left(\Delta \mathrm{t}_{\mathrm{R}}=0.41 \mathrm{~min}\right)$ prompted us to consider it as a new compound. MS/MS spectra of the above compounds were almost identical to that of sennoside A, indicating that they could be close isomers. Although the precise structures have not been determined, we believe that the structural diversity may derive from different hexosyl substituents or substitution positions. Another isomer (S18) of sennoside A appeared at $16.88 \mathrm{~min}$ in the chromatogram of $R$. officinale (Figure ${ }^{\circ} 2$ ). ${ }^{\circ} \mathrm{It}^{\circ}$ gave $^{\circ}$ an $^{\circ}$ abundant $^{\circ}$ ion $^{\circ}$ at $^{\circ} \mathrm{m} / \mathrm{z} 386$ (18\% rel. int.) in the MS/MS spectrum, while this ion was very weak for the above isomers $(<5 \%)$. We presume that S18 may be sennoside B, where the two anthrone rings are in erythro form, in contrast to threo (or trans) form in sennoside A. The erythro-configuration may cause sennoside $B$ to be less stable, and its $C_{10}-C_{10}$, bond is easier to be cleaved than sennoside $A$ to produce the $m / z 386$ ion.

The contents of sennoside A in official rhubarbs have previouslygeen ${ }^{\circ}$ determined to be $0.5-2.0 \% 91,912,13,25$, 26]..$^{\circ}$ Given ${ }^{\circ}$ the ${ }^{\circ}$ fact $^{\circ}$ that ${ }^{\circ}$ sennoside ${ }^{\circ} \mathrm{A}^{\circ}$ was $^{\circ}$ only ${ }^{\circ}$ detected in $R$. officinale at moderate level in this study, the previous results may be inaccurate and should be reevaluated. Considering the complexity of chemical composition of rhubarbs, it is very likely that different isomers or interfering compounds were taken as sennoside A in previous UV-based analysis. Furthermore, we noticed that the contents of S8 in $R$. palmatum and $R$. tanguticum were about 10-fold higher than that of sennoside $A$ in $R$. officinale, determined by their peak areas $^{\circ}\left(\right.$ Figure $\left.^{\circ} 2\right) .^{\circ}$ This $^{\circ}$ result $^{\circ}$ is ${ }^{\circ}$ consistent $^{\circ}$ with $^{\circ} \mathrm{Xiao}^{\prime} \mathrm{s}$ report that $R$. officinale showed weaker purgative effects than ${ }^{\circ}$ the $^{\circ}$ other $^{\circ}$ species $^{\circ}[1]$.

Similar to sennoside A isomers, the ion chromatograms for $m / z 847$ corresponding to sennosides C and D also showed difference for the species studied. Only one major peak (S1, $6.16 \mathrm{~min})$ was observed in $R$. officinale, whereas at least two compounds were detected in R. palmatum and R. tanguticum (S3 at $6.31 \mathrm{~min}$ and S7 at $8.36 \mathrm{~min})$. The relative contents of S3 and S7 for the latter two species were remarkably higher than that of S1. In addition, these compounds gave a significant $m / z 386$ ion in their MS/MS spectra, while the minor isomers at $11.73 \mathrm{~min}$ (S9) and $12.90 \mathrm{~min}$ (S14) produced an ion at $m / z 416$. Both ions should originate from $C_{10}-C_{10}$ cleavage, and the difference in MS fragmentation behavior may be attributed to $C_{10}-C_{10}$ configuration of the isomers.

Besides the above described major sennosides, a number of minor sennosides were identified from rhubarbs. Two isomers (S23 and S28) were observed in the XIC for $m / z 699$ of $R$. palmatum. They could be deglucosylated derivatives of sennoside A. S23 at $20.83 \mathrm{~min}$ gave a weak $m / z 386$ signal (10\% rel. int.) in the MS/MS spectrum, while S28 at $26.61 \mathrm{~min}$ yielded $\mathrm{m} / \mathrm{z} 386$ as the base peak. This result is correlated with that of sennoside $\mathrm{A}$ isomers described above. In addition, we identified sennosides with a $-\mathrm{CH}_{3}$ group at $\mathrm{C}-3$. These compounds produced an $[\mathrm{M}-\mathrm{H}]^{-}$ion at $m / z 831$ or $m / z 669$, and characteristic $m / z 386$ ion in the MS/MS spectra. For another two minor sennosides, base peaks due to the direct loss of a carboxyl group $(\Delta \mathrm{m}=44 \mathrm{u})$ from $[\mathrm{M}-\mathrm{H}]^{-}$were observed in the MS/MS spectra. This fragmentation was followed by significant loss of $204 \mathrm{u}$. These evidences suggested the presence of a malonyl group in the structures. Malonyl group had been reported in anthraquinone glycosides isolated from $^{\circ} R$. qinlingense [27]. ${ }^{\circ}$ Similarly, ${ }^{\circ}$ sennosides ${ }^{\circ}$ with $^{\circ}$ an acetyl group on the glucosyl residue were characterized by direct loss of $204 \mathrm{u}$ from $[\mathrm{M}-\mathrm{H}]^{-}$ions. Most of these minor sennosides were reported from rhubarbs for the first time. Due to their low contents, however, these compounds showed little taxonomic significance for rhubarbs.

\section{ESI-MS/MS of Free Anthraquinones}

The mass spectra of five free anthraquinones identified in ${ }^{\circ}$ hubarb ${ }^{\circ}$ are $^{\circ}$ shown $^{\circ}$ in ${ }^{\circ}$ Figure $^{\circ}$. $^{\circ}$ ESI-MS ${ }^{\circ}$ of ${ }^{\circ}$ anthraquinones appeared to provide more structural information than $^{\circ} \mathrm{APCI}-\mathrm{MS}^{\circ} \mathrm{did}^{\circ} \mathrm{as}^{\circ}$ reported $^{\circ}$ previously $^{\circ}[28] .{ }^{\circ}$ In $^{\circ}$ the MS/MS spectrum of chrysophanol, a product ion at $\mathrm{m} / \mathrm{z}$ 225 was observed, resulting from the direct loss of $\mathrm{CO}$ from $[\mathrm{M}-\mathrm{H}]^{-}$. The $m / z 225$ ion was very stable and did 


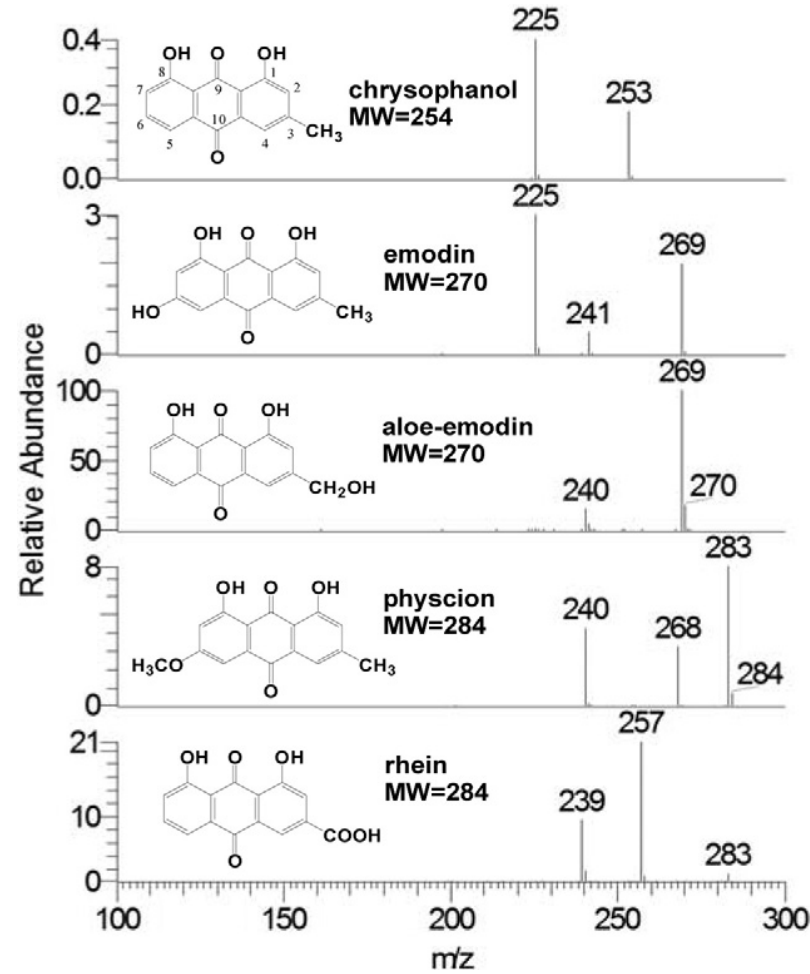

Figure 3. ESI-MS/MS spectra for the $[\mathrm{M}-\mathrm{H}]^{-}$ions of free anthraquinones.

not yield any further fragmentation. We believe that the $\mathrm{CO}$ elimination may originate from $\mathrm{C}-10$, since the carbonyl group at C-9 has intramolecular hydrogen bonding with the $\alpha$-hydroxyl groups at C- 1 and C-8 and is, thus, difficult to be cleaved.

Emodin and aloe-emodin, as well as physcion and rhein are isomers. They could be differentiated by their ESI-MS/MS spectra, respectively. The fragmentation of emodin was initiated by the elimination of $\mathrm{CO}$ to produce $\mathrm{m} / \mathrm{z} 241$, and followed by loss of one hydroxyl group to give $m / z 225$. The $[\mathrm{M}-\mathrm{H}]^{-}$ion of aloeemodin, however, only produced one fragment at $\mathrm{m} / \mathrm{z}$ $240\left([\mathrm{M}-\mathrm{H}-\mathrm{CHO}]^{-}\right)$. Physcion contains a methoxyl group, and easily eliminated 15 mass units to give a significant ion at $m / z 268$. This ion could further lose one molecule of CO to produce $\mathrm{m} / \mathrm{z} 240$. Rhein, however, gave two ions at $\mathrm{m} / \mathrm{z} 257$ and $\mathrm{m} / \mathrm{z} 239$ in the MS/MS spectrum. They could result from degradation of the benzene ring $\left(-\mathrm{C}_{2} \mathrm{H}_{2}\right)$ and cleavage of the carboxyl group $\left(-\mathrm{CO}_{2}\right)$, respectively. The obvious difference in MS/MS spectra between isomers sufficed their discrimination, and was valuable for the identification of their corresponding glycosides, as described later in this paper.

\section{Identification of Free Anthraquinones in Rhubarbs}

A total of seven free anthraquinones were detected in this study. Five of them, chrysophanol, emodin, aloeemodin, physcion, and rhein were unambiguously characterized by comparing their HPLC retention times and mass spectra with those of pure standards. Two unknown free anthraquinones were also detected. Since $\left[\mathrm{M}-\mathrm{H}-\mathrm{CH}_{3}\right]^{-}$ions were observed in their MS/MS spectra, we believe them to be isomers of physcion, with a methoxyl group located at C-1 or C-8. It should be noted that although free anthraquinones were used as marker compounds for quality control of rhubarbs in most previous reports, they were only detected in the crude drugs at moderate to low levels. Emodin and chrysophanol were the most abundant ones, and their presence did not show significant differences among the six species studied (Figure S-2). However, rhein was observed at desirable levels in Sect. Palmata species, but was hardly detected in Sect. Rheum, consistent with the observations ${ }^{\circ} \operatorname{made}^{\circ}$ by $^{\circ} \mathrm{Xiao}^{\circ} \mathrm{et}^{\circ}{ }^{\circ} \mathrm{l}^{\circ}[1]$. .Therefore, $^{\circ}$ aside from sennosides, rhein could be considered as a marker for the differentiation of official and unofficial rhubarbs.

\section{Identification of Anthraquinone Glycosides}

Similar to free anthraquinones, anthraquinones glycosides easily produced $[\mathrm{M}-\mathrm{H}]^{-}$ions in the negative ESI source. Their MS/MS fragmentations were predominated by the elimination of glucosyl residue to give $[\text { Aglycone- } \mathrm{H}]^{-}\left([\mathrm{A}-\mathrm{H}]^{-}\right)$ions as the base peak. The aglycones were identified based on the product ion spectra of $[\mathrm{A}-\mathrm{H}]^{-}$ions, and by referring to the MS fragmentation behaviors of free anthraquinones described above. In this study, 13 anthraquinone glycosides were identified. Their structures and mass spectral $^{\circ}$ data $^{\circ}$ are $^{\circ}$ given ${ }^{\circ}{ }^{\circ}{ }^{\circ}$ Table $^{\circ} 1$.

Emodin 8-O-glucoside $\left(\mathrm{MW}=432, \mathrm{t}_{\mathrm{R}}=20.01 \mathrm{~min}\right)$ was identified as a major anthraquinone glycoside in all the six studied rhubarbs by comparing its HPLC retention time and mass spectra with those of a pure standard. Aside from emodin 8-O-glucoside, another abundant compound was detected at $19.45 \mathrm{~min}$ in the $\mathrm{m} / \mathrm{z} 431^{\circ} \mathrm{Chromatogram}{ }^{\circ}{ }^{\circ}$ or ${ }^{\circ} \mathrm{R}$. officinale (Figure ${ }^{\circ} 4$ ). ${ }^{\circ}$ Its MS/MS spectrum showed ions at $\mathrm{m} / \mathrm{z} 269$ and $\mathrm{m} / \mathrm{z}$ 268. The $\mathrm{MS}^{3}$ spectrum of $m / z 268$ gave a fragment at $\mathrm{m} / \mathrm{z} 224$, indicating the aglycone to be emodin. Based on these evidences, the latter compound was tentatively identified as emodin 1-O-glucoside, which had been previously detected as a major constituent in $R$. officinale [29]..$^{\circ}$ Two $^{\circ}$ minor $^{\circ}$ isomers ${ }^{\circ}$ of $^{\circ}$ emodin $^{\circ}$ glucoside (12.97 $\mathrm{min}$ and $13.31 \mathrm{~min}$ ) were also detected in $^{\circ}$ the $^{\circ}$ rhubarbs $^{\circ}\left(\right.$ Figure $\left.^{\circ} 4\right)$.

In the XIC for $m / z 517$, all the six rhubarb species except $R$. officinale gave a peak at $22.62 \mathrm{~min}$. MS/MS spectrum of this compound showed a base peak at $m / z 473$, due to the loss of a carboxyl group. The $\mathrm{m} / \mathrm{z}$ 473 ion could further eliminate $204 \mathrm{u}$ to produce $\mathrm{m} / \mathrm{z}$ 269. These fragmentations suggested the presence of a malonyl substituent on the glucosyl residue. The $\mathrm{MS}^{3}$ spectrum of $\mathrm{m} / \mathrm{z} 269$ gave a signal at $\mathrm{m} / \mathrm{z} 225$, indicating the aglycone to be emodin. Thus, this 
Table 1. Identification of anthraquinone glycosides in rhubarbs

\begin{tabular}{|c|c|c|c|c|c|c|c|c|c|}
\hline \multirow[b]{2}{*}{$\mathrm{t}_{\mathrm{R}}(\min )$} & \multirow[b]{2}{*}[\mathrm{M}-\mathrm{H}]{$^{-}$} & \multirow[b]{2}{*}{ Identification } & \multicolumn{6}{|c|}{ Rheum sp. } & \multirow[b]{2}{*}{$\mathrm{MS}^{\mathrm{n}}$} \\
\hline & & & $\mathrm{RO}^{\mathrm{b}}$ & $\mathrm{RP}^{\mathrm{b}}$ & $\mathrm{RT}^{\mathrm{b}}$ & $\mathrm{RF}^{\mathrm{b}}$ & $\mathrm{RH}^{\mathrm{b}}$ & $\mathrm{RE}^{\mathrm{b}}$ & \\
\hline $6.27 *$ & 445 & Rhein 8-O-glucoside & + & - & - & - & - & - & $\begin{array}{l}\mathrm{MS}^{2}[445]: 325(5), 283(100), 269(25) \\
\quad \operatorname{MS}^{3}[283]: 257(60), 239(100)\end{array}$ \\
\hline 7.33 & 445 & Rhein 1-O-glucoside & - & + & + & - & - & - & $\begin{array}{l}\mathrm{MS}^{2}[445]: 325(15), 283(100), 269(25) \\
\mathrm{MS}^{3}[283]: 257(45), 239(100)\end{array}$ \\
\hline 10.26 & 487 & Rhein $1-O-(O$-acetyl)-glucoside & - & + & - & - & - & - & $\begin{array}{l}\mathrm{MS}^{2}[487]: \\
267(20), 239(15), 283(100), 269(30) \\
\mathrm{MS}^{3}[283]: \\
257(50), 239(100)\end{array}$ \\
\hline 10.97 & 473 & $\begin{array}{l}\text { Aloe-emodin 8-O-(6'-O-acetyl)- } \\
\text { glucoside }\end{array}$ & - & + & - & - & - & - & $\begin{array}{l}\operatorname{MS}^{2}[473]: 311(10), 269(100) \\
\operatorname{MS}^{3}[269]: 240(20)\end{array}$ \\
\hline 11.37 & 487 & Rhein $1-O-(O$-acetyl)-glucoside & - & + & + & - & - & - & $\begin{array}{l}\mathrm{MS}^{2}[487]: 325(10), 283(80), 269(25), \\
\text { 239(100) } \\
\mathrm{MS}^{3}[283]: 257(35), 239(100)\end{array}$ \\
\hline 12.97 & 431 & Emodin-O-glucoside & + & - & - & - & + & + & $\begin{array}{l}\mathrm{MS}^{2}[431]: 269(100) \\
\mathrm{MS}^{3}[269]: 225(2)\end{array}$ \\
\hline 13.31 & 431 & Emodin-O-glucoside & - & + & + & + & - & - & $\begin{array}{l}\operatorname{MS}^{2}[431]: 269(100) \\
\operatorname{MS}^{3}[269]: 225(8)\end{array}$ \\
\hline 19.30 & 415 & Chrysophanol 1-O-glucoside & + & + & + & + & + & + & $\mathrm{MS}^{\mathrm{n}}$ not available \\
\hline 19.45 & 431 & Emodin 1-O-glucoside & + & - & - & - & - & - & $\begin{array}{l}\operatorname{MS}^{2}[431]: 269(15), 268(100) \\
\operatorname{MS}^{3}[268]: 224(1)\end{array}$ \\
\hline $20.01^{a}$ & 431 & Emodin 8-O-glucoside & + & + & + & + & + & + & $\begin{array}{l}\operatorname{MS}^{2}[431]: 311(12), 269(100) \\
\operatorname{MS}^{3}[269]: 241(2), 225(15)\end{array}$ \\
\hline $20.53^{a}$ & 415 & Chrysophanol 8-O-glucoside & + & + & + & + & + & + & $\mathrm{MS}^{\mathrm{n}}$ not available \\
\hline 22.62 & 517 & $\begin{array}{l}\text { Emodin 8-O-(6'-O-malonyl)- } \\
\text { glucoside }\end{array}$ & + & + & + & + & + & + & $\begin{array}{l}\operatorname{MS}^{2}[517]: 473(100) \\
\operatorname{MS}^{3}[473]: 311(10), 269(100) \\
\operatorname{MS}^{4}[269]: 225(10)\end{array}$ \\
\hline 22.88 & 567 & $\begin{array}{l}\text { Chrysophanol 8-O-(6'-O- } \\
\text { galloyl)-glucoside }\end{array}$ & + & + & + & + & + & + & $\begin{array}{l}\mathrm{MS}^{2}[567]: 313(100), 271(20), 253(8), \\
211(6), 169(10) \\
\mathrm{MS}^{3}[313]: 253(3), 241(10), 211(6), \\
\text { 193(2), 169(100), 125(15) } \\
\mathrm{MS}^{4}[169]: 125(100)\end{array}$ \\
\hline
\end{tabular}

${ }^{\mathrm{a}}$ Compounds confirmed by comparing with pure standards.

${ }_{\mathrm{R}}^{\mathrm{RO}}=$ Rheum officinale; $\mathrm{RP}=R$. palmatum; $\mathrm{RT}=R$. tanguticum; $\mathrm{RF}=R$. franzenbachii; $\mathrm{RH}=R$. hotaoense; $\mathrm{RE}=R$. emodi.

compound was tentatively characterized as emodin 8-O-(6' ○O-malonyl)-glucoside ${ }^{\circ}\left(\right.$ Table $\left.^{\circ} 1\right) .^{\circ}$ The $^{\circ} \mathrm{m} / z 517$ chromatogram for $R$. officinale, however, gave a peak at $22.50 \mathrm{~min}$, slightly different from the above isomers $\left(t_{R}=22.62 \pm 0.02 \mathrm{~min}\right)$. When the high amount of emodin 1-O-glucoside in $\mathrm{R}$. officinale is considered, this compound may be emodin 1-O-(6'-O-malonyl)glucoside, which showed very similar mass spectra to its 8-glucosyl isomer.

In the XIC for $m / z 445$, each species from Sect. Palmata gave one significant peak, though at different retention $^{\circ}$ times $^{\circ}\left(\right.$ Figure $\left.^{\circ} 4\right){ }^{\circ}{ }^{\circ}$ The $^{\circ}$ peak $^{\circ}$ in $^{\circ} R$. officinale appeared at $6.27 \mathrm{~min}$ and was identified as rhein 8 -O-glucoside by comparing with a pure standard. The peaks in $R$. palmatum and $R$. tanguticum, however, appeared at $7.33 \mathrm{~min}$. Their MS/MS spectrum yielded $\mathrm{m} / \mathrm{z} 283$ as the base peak, which could further fragment into $\mathrm{m} / \mathrm{z} 257$ and $\mathrm{m} / \mathrm{z} 239$. These cleavages were similar to those of rhein. Thus, the corresponding compound was tentatively identified as the known rhein 1-Oglucoside.

From the above results, one can find that anthraquinone glycosides in $R$. officinale are remarkably different from those in $R$. palmatum and R. tanguticum. The different rhubarb species examined showed significant selectivity in glucosylation positions. The predominant components in $R$. officinale were found to be rhein 8-O-glucoside and emodin 1-O-glucoside (tentatively assigned), while those for the other two species were rhein 1-O-glucoside and emodin 8-O-glucoside. In spite of the very similar HPLC retention times and mass spectra for each pair of isomers, our LC/MS method succeeded in telling them apart explicitly. This is the first report on the difference in anthraquinone glycosides among official rhubarbs.

Aside from the above major glycosides of emodin and rhein, two chrysophanol glycosides were detected in all the six rhubarb species. These glycosides gave an $[\mathrm{M}-\mathrm{H}]^{-}$ion at $\mathrm{m} / \mathrm{z} 415$. One of them was identified as chrysophanol 8-O-glucoside by comparing with a pure standard. The other compound was tentatively characterized as chrysophanol 1-O-glucoside since it showed very similar mass spectra. Only one glycoside of aloe-emodin was detected in R. palmatum, and was plausibly identified as aloe-emodin $8-\mathrm{O}-\left(6^{\prime}-\mathrm{O}-\right.$ acetyl)-glucoside. 


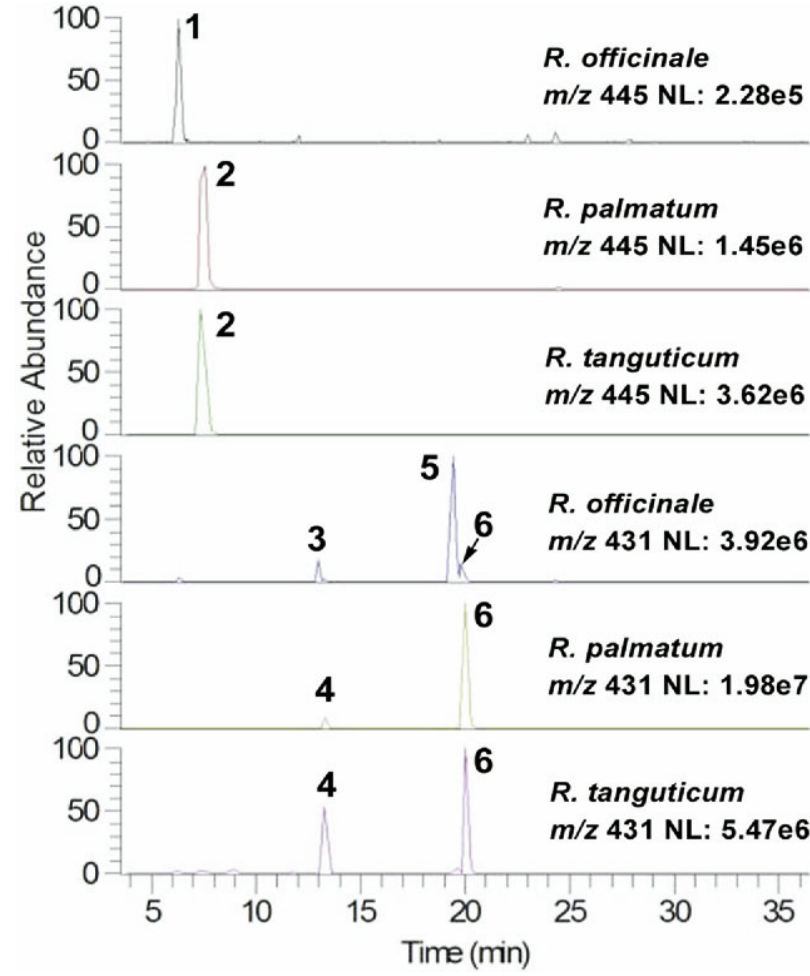

Figure 4. Extracted ion chromatograms for $\mathrm{m} / \mathrm{z} 445$ and 431 of different official rhubarb species. $\mathbf{1}=$ rhein 8 -O-glucoside $(6.27$ min), 2 = rhein $1-O$-glucoside $(7.33 \mathrm{~min}$, plausible), $\mathbf{5}=$ emodin 1-O-glucoside (19.45 min, plausible), $6=$ emodin 8 -O-glucoside (20.01 $\mathrm{min}), 3(12.97 \mathrm{~min})$ and $4(13.31 \mathrm{~min})$ are unidentified emodin glycosides.

\section{Identification of Stilbenes}

As pure standards were unavailable, stilbenes in rhubarbs were identified on the basis of their mass spectra and by referring to the literature. A total of 34 stilbenes were identified in this study (Table S-2).

Most stilbenes identified occurred as glycosides. Their $[\mathrm{M}-\mathrm{H}]^{-}$ions readily eliminated a glucosyl residue $(162 \mathrm{u})$ to produce $[\mathrm{A}-\mathrm{H}]^{-}$. The aglycones were identified based on $\mathrm{MS}^{3}$ spectra of the $[\mathrm{A}-\mathrm{H}]^{-}$ ions. So far, aglycones reported from rhubarbs include resveratrol, piceatannol, rhapontigenin, isorhapontigenin, and deoxyrhapontigenin. Resveratrol was characterized by the neutral loss of $42 \mathrm{u}\left(\mathrm{C}_{2} \mathrm{H}_{2} \mathrm{O}\right)$, consistent with $^{\circ}$ previous ${ }^{\circ}$ reports $\left[30,{ }^{\circ} 31\right] .{ }^{\circ}$ Piceatannol, ${ }^{\circ}$ which ${ }^{\circ}$ contains $3^{\prime}, 4^{\prime}$-dihydroxyl groups, could eliminate one molecule of $\mathrm{H}_{2} \mathrm{O}$ to produce $\mathrm{m} / \mathrm{z} 225$. The other three aglycones contain a methoxyl group, and are easy to lose 15 mass units upon collision energy.

Some stilbenes in rhubarb were esterified with gallic acid, cinnamic acid, or $p$-coumaric acid on the glucosyl residue. The ester side chains were identified by MS, since the phenolic groups were easy to be charged and thus provided abundant information. When a galloyl group was present, the ion at $\mathrm{m} / \mathrm{z} 313$ ([galloylglucose $\mathrm{H}]^{-}$) appeared as base peak in the MS/MS spectrum. It could further fragment into $\mathrm{m} / \mathrm{z} 169$ ([gallic acid $-\mathrm{H}]^{-}$) and $m / z$ 125. The structural elucidation was exemplified by piceatannol $4^{\prime}-\mathrm{O}-\left(6^{\prime \prime}-\mathrm{O}\right.$-galloyl)-glucoside in Figure S-3. Similarly, the presence of $p$-coumaroyl group were characterized by the abundant ions at $\mathrm{m} / \mathrm{z} 307$ ([pcoumaroylglucosyl $\left.-\mathrm{H}]^{-}\right), \mathrm{m} / \mathrm{z} 163$ ([p-coumaric acid $\mathrm{H}]^{-}$), and $m / z 145$. When cinnamoyl group was present, however, only $[\mathrm{A}-\mathrm{H}]^{-}$ions were observed, since cinnamic acid does not contain any hydroxyl group and is difficult to be charged. Stilbenes substituted with acetyl glucose were characterized by the significant loss of $204 \mathrm{u}$ in MS/MS spectra. In addition, one stilbene ([M $-\mathrm{H}]^{-} \mathrm{m} / \mathrm{z}$ 595, $21.92 \mathrm{~min}$ ) with a feruoyl substituent was identified in rhubarb for the first time. Its MS/MS spectrum gave characteristic ions at $\mathrm{m} / \mathrm{z} 337$ ([feruoylglucose $-\mathrm{H}^{-}$), $m / z 193$ ([ferulic acid $\left.-\mathrm{H}\right]^{-}$), and $m / z 175$.

Rhaponticin (MW $=420)$ is considered to be a major constituent of unofficial rhubarbs, and is used to differentiate them from official species. Surprisingly, we found that the three unofficial species exhibited different profiles in the XIC for $m / z$ 419. $R$. franzenbachii gave a major peak at $10.78 \mathrm{~min}$, while the major peak for the other $^{\circ}$ two $^{\circ}$ species $^{\circ}$ appeared ${ }^{\circ}$ at $^{\circ} 10.31^{\circ}$ min $^{\circ}\left(\right.$ Figure $^{\circ} 5$ ). Although their MS information were almost identical, the difference of $0.5 \mathrm{~min}$ in retention times led us to believe that these two peaks represented different compounds. Similar difference was observed for the other major stilbene corresponding to piceatannol glucosides $(\mathrm{MW}=406)$. In the XIC for $\mathrm{m} / \mathrm{z} 405, R$. franzenbachii showed a significant peak at $7.42 \mathrm{~min}$, while the other two ${ }^{\circ}$ species ${ }^{\circ}$ gave $^{\circ} a^{\circ}$ peak $^{\circ} a^{\circ}{ }^{\circ} 6.18^{\circ} \mathrm{min}^{\circ}$ (Figure ${ }^{\circ}$ ).

Thus, the stilbenes detected in $R$. franzenbachii differed mostly from those detected in $R$. hotaoense and $R$. emodi. Although precise structures of these stilbenes have not been determined yet, we believe that they may be pairs of close isomers present in different species separately.

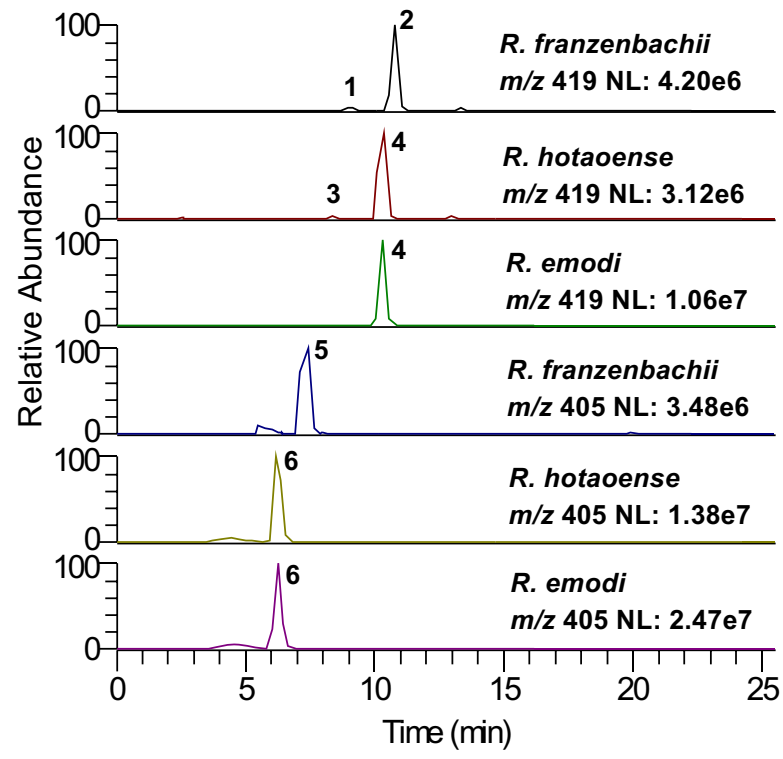

Figure 5. Extracted ion chromatograms for $\mathrm{m} / \mathrm{z} 419$ and 405 in unofficial rhubarbs. Peaks 1-4 are rhaponticin or its isomers; peaks 5 and 6 represent piceatannol-O-glucosides. 
Stilbenes have seldom been reported for Sect. Palmata. However, several resveratrol derivatives were identified in this study. One abundant peak in the XIC for $m / z 389$ of $R$. tanguticum was tentatively identified as resveratrol ${ }^{\circ} 4^{\prime}$-O-glucoside, ${ }^{\circ}$ which ${ }^{\circ}$ was $^{\circ}$ recently ${ }^{\circ}$ isolated from ${ }^{\circ}$ this $^{\circ}$ species $^{\circ}[32]$.

\section{Identification of Glucose Gallates}

Galloyl esters of glucose are an important class of phenolic compounds that show great potential for the treatment ${ }^{\circ}$ of $^{\circ}$ cancer $^{\circ}$ and $^{\circ}$ diabetes $^{\circ}\left[33,{ }^{\circ} 34\right]^{\circ} . .^{\circ}{ }^{\circ}$ this ${ }^{\circ}$ study, we found that glucose gallates represented major constituents of both official and unofficial rhubarbs. A total of 19 glucose gallates were identified by LC/MS from the six species studied, and may be responsible for their antitumor activities (Table S-3). All these compounds were found to contain at least one galloyl group on the glucose. According to the literature, the galloyl group can be located at C-1, C-2, or C-6, though the precise location ${ }^{\circ}$ could $^{\circ}$ not $^{\circ}$ be $^{\circ}$ confirmed $^{\circ}$ in $^{\circ}$ this ${ }^{\circ}$ study ${ }^{\circ}\left[4,{ }^{\circ} 5\right] .{ }^{\circ}$ By analyzing the mass spectra, we found that some gallates were esterified with hydroxycinnamic acids, including cinnamic acid, $p$-coumaric acid, and ferulic acid. The ester chains were identified in the same way as described above for stilbene glycosides with galloyl substituents. For instance, the loss of 152 or $170 \mathrm{u}$ from [M$\mathrm{H}]^{-}$, together with the abundant [gallic acid $\left.-\mathrm{H}\right]^{-}$ion in the MS/MS spectra could lead to the identification of a galloyl group.

Although glucose gallates were detected in all the rhubarb species studied, R. palmatum and R. tanguticum contained more gallates than $R$. officinale and Sect. Rheum. The major gallates identified from the three official species are illustrated in Figure S-4. One can find that the profiles of $R$. palmatum and $R$. tanguticum were similar to each other, but different from that of $R$. officinale. The most abundant gallate in $R$. officinale was identified as the known 1-O-galloyl-6-O-cinnamoyl-glucose $\left([\mathrm{M}-\mathrm{H}]^{-}, m / z 461\right)$. The two abundant analogs in R. palmatum and R. tanguticum $\left([\mathrm{M}-\mathrm{H}]^{-}, m / z 623\right.$ and $\mathrm{m} / \mathrm{z}$ 607), however, have not been reported previously. According to the mass spectra, the $m / z 623$ compound was identified as a glucose gallate containing two $p$-coumaroyl group, while the $m / z 607$ analog contained one $p$-coumaroyl group and one cinnamoyl group.

\section{Identification of Other Compounds}

Two naphthalenes, torachrysone 8-O-glucoside (19.11 min, $\left.[\mathrm{M}-\mathrm{H}]^{-} \mathrm{m} / \mathrm{z} 407\right)$ and torachrysone 8-O-(6'-Oacetyl)-glucoside (22.68 $\left.\mathrm{min},[\mathrm{M}-\mathrm{H}]^{-} \mathrm{m} / \mathrm{z} 449\right)$, were detected in all six rhubarb species in similar yields (Figure S-5). Their structures were established based on the characteristic MS fragmentations. Upon collisioninduced dissociation (CID), the $[\mathrm{M}-\mathrm{H}]^{-}$ion at $m / z 407$ eliminated one molecule of glucose to produce $m / z 245$. The $m / z 245$ ion could further lose two methyl groups successively to give significant $\mathrm{m} / \mathrm{z} 230$ and $\mathrm{m} / \mathrm{z} 215$ ions.
Table 2. Comparison of phenolic compounds in rhubarbs from Sect. Palmata and Sect. Rheum

\begin{tabular}{lcc}
\hline \multicolumn{1}{c}{ Compounds } & Sect. Palmata & Sect. Rheum \\
\hline \hline Sennosides & + & - \\
Free anthraquinones & + & + \\
Anthraquinone glycosides & ++ & + \\
Stilbenes & \pm & ++ \\
Glucose galloyl esters & ++ & + \\
Naphthalenes & + & + \\
\hline
\end{tabular}

Note: ++ , major components; + , present; \pm , present in minute amounts; -, absent.

We believe that the methyl groups may originate from the methoxyl and acetyl groups. The aglycone, torachrysone, was only detected at high level in $R$. officinale $\left([\mathrm{M}-\mathrm{H}]^{-} m / z 245\right)$.

Epi-catechin and its gallates were also identified in rhubarb species. Their structures were identified by comparing $^{\circ}$ the $^{\circ}$ mass $^{\circ}$ spectra $^{\circ}$ with ${ }^{\circ}$ literature ${ }^{\circ}$ data $^{\circ}[35]$.

\section{Comparison of Phenolic Compounds in Different Rhubarbs}

Based on our LC/MS analysis, we can find that phenolic compounds of different rhubarbs showed taxonomic ${ }^{\circ}$ significance, ${ }^{\circ}$ as $^{\circ}$ summarized $^{\circ}$ in $^{\circ}$ Table $^{\circ} 2 .^{\circ}$ Official and unofficial rhubarbs were able to be differentiated according to the presence of sennosides and rhein derivatives. Anthraquinones, glucose gallates, and naphthalenes, were ubiquitously identified in all species studied. Stilbenes were found to be the major components of Sect. Rheum, while a minute amount was also observed in Sect. Palmata. Furthermore, we discovered for the first time differences in phenolic compounds for the three official rhubarbs. The same sennosides, anthraquinone glycosides, and glucose gallates were detected in R. palmatum and R. tanguticum, while a very different profile was observed for $R$. officinale. Based on the MS information, we believe that the differences in chemical composition were mostly attributed to the presence of isomers in different species. It was noteworthy that sennoside $\mathrm{A}$, which has been considered as the major purgative compound of rhubarb, was only observed in R. officinale, and its isomers were detected in the other two official species at high levels. Similarly, the predominant anthraquinone glycosides in $R$. officinale were found to be rhein 8-Oglucoside and emodin 1-O-glucoside, while those in $R$. palmatum and $R$. tanguticum were rhein 1-O-glucoside and emodin 8-O-glucoside. Considering that $R$. officinale is mainly grown in the southern part of China, while the other two species are indigenous to the north, we suggest that they may be differentiated into two herbs under the name of "South Rhubarb" and "North Rhubarb", respectively. Interestingly, this nomenclature has been used in folk herbal market for hundreds of years. Since the contents of most phenolic compounds in $R$. palmatum and $R$. tanguticum were around 10-fold higher 
than those in R. officinale, "North Rhubarb" could be superior to "South Rhubarb" in quality. However, pharmacological evaluations were needed before we can make the final conclusion.

For unofficial rhubarbs, substantial differences were also observed among the species, especially for stilbenes. It appeared that $R$. hotaoense and $R$. emodi were more similar to each other in chemical compositions, but different from $R$. franzenbachii. Biological activities of these species have not been fully investigated yet. However, the detection of abundant stilbenes from these unofficial rhubarbs in this study suggested their great potential as new herbal drugs for the treatment of hyperlipidemia, obesity, and diabetes.

The problem of multi-source is commonly seen for Chinese medicine. Physically similar plants from the same or even different genera are used as the same herb. The difference in chemical compositions of various species may lead to different biological activities. Today, multi-sourcing has been a major cause of clinical accidents in phytotherapy. Our strategy here for rhubarb investigation may be used for rapid and accurate discrimination of different herb species, and thus improve the therapeutic safety of herbal treatments.

\section{Conclusions}

A simple and rapid LC/MS method has been established for the first comprehensive analysis of phenolic compounds in official and unofficial rhubarbs. Although sennosides, anthraquinones, and stilbenes had been investigated previously, a number of new analogs were detected with the LC/MS method. Galloyl esters of glucose were found to be a new type of main constituents of both official and unofficial rhubarbs, and may be responsible for their antitumor effects. By comparing chemical profiles of the rhubarb species, we found that their phenolic patterns showed significant difference. Based on the findings that $R$. officinale contains different purgative compounds (sennosides and anthraquinones) from $R$. palmatum and R. tanguticum, we recommend that these species be used separately in clinical practices. Since the contents of sennosides and anthraquinones in $R$. officinale are apparently lower than those in the other two species, it may be inferior as a plant source for rhubarb drugs. From the unofficial rhubarbs studied, new abundant stilbenes were identified by LC/MS. The results suggested that these unofficial species cannot be used as purgative agents, but may be developed as new herbal drugs for the treatment of diabetes and hyperlipidemia. All the studied species can be explicitly differentiated by the established LC/MS method. Our results may also be useful for quality control of rhubarb drugs, so as to guarantee their safe use in phytotherapies. Due to the obvious chemical differences, a comprehensive pharmacological evaluation of different rhubarbs is greatly needed for a more rational and accurate clinical application of this important herbal medicine.

\section{Acknowledgments}

The authors thank Dr. Hongzhu Guo and Dr. Guoqiang Fan for providing part of the pure standards. MY is grateful to Dr. Angelika Hofmann for her guidance in correcting the manuscript.

\section{References}

1. Xiao, P.; He, L.; Wang, L. Ethnopharmacologic Study of Chinese Rhubarb. J. Ethnopharmacol. 1984, 10, 275-293.

2. Duke, J. A. Handbook of Medicinal Herbs, 2nd ed.; CRC Press: Boca Raton, FL, 2002; p 621.

3. China Pharmacopoeia Committee. Pharmacopoeia of the People's Republic of China, 2005 ed.; Chemical Industry Press: Beijing, 2005; p 17.

4. Kashiwada, Y.; Nonaka, G. I.; Nishioka, I.; Yamagishi, T. Galloyl and Hydroxycinnamoylglucoses from Rhubarb. Phytochemistry 1988, 27, 1473-1477.

5. Abe, I.; Seki, T.; Noguchi, H.; Kashiwada, Y. Galloyl Esters from Rhubarb are Potent Inhibitors of Squalene Epoxidase, a Key Enzyme in Cholesterol Biosynthesis. Planta Med. 2000, 66, 753-756.

6. Tsuboi, M.; Minami, M.; Nonaka, G. I.; Nishioka, I. Studies on Rhubarb (Rhei rhizoma). IV. Naphthalene Glycosides. Chem. Pharm. Bull. 1977, 25, 2708-2712.

7. Kashiwada, Y.; Nonaka, G.; Nishioka, I. Tannins and Related Compounds 45.Rhubarb.5. Isolation and Characterization of Flavan-3-ol and Procyanidin Glucosides. Chem. Pharm. Bull. 1986, 34, 3208-3222.

8. Matsuda, H.; Morikawa, T.; Toguchida, I.; Park, J. Y.; Harima, S.; Yoshikawa, M. Antioxidant Constituents from Rhubarb: Structural Requirements of Stilbenes for the Activity and Structures of Two New Anthraquinones Glucosides. Bioorg. Med. Chem. 2001, 9, 41-50.

9. Jang, M.; Cai, L.; Udeani, G. O.; Slowing, K. V.; Thomas, C. F.; Beecher, C. W. W.; Fong, H. H. S.; Farnsworth, N. R.; Kinghorn, A. D.; Mehta, R. G.; Moon, R. C.; Pezzuto, J. M. Cancer Chemopreventive Activity of Resveratrol, a Natural Product Derived from Grapes. Science 1997, 275, $218-220$.

10. Lee, S. H.; Ryu, S. Y.; Kim, H. B.; Kim, M. Y.; Chun, Y. J. Induction of Apoptosis by 3,4'-Dimethoxy-5-Hydroxystilbene in Human Promyeloid Leukemic HL-60 Cell. Planta Med. 2002, 68, 123-127.

11. Zhang, H. X.; Liu, M. C. Separation Procedures for the Pharmacologically Active Components in Rhubarb. J. Chromatogr. B. 2004, 812, 175-181.

12. Kuo, C. H.; Sun, S. W.Analysis of Nine Rhubarb Anthraquinones and Bianthrones by Micellar Electrokinetic Chromatography Using Experimental Design. Anal. Chim. Acta 2003, 482, 47-58.

13. Koyama, J.; Morita, I.; Fujiyoshi, H.; Kobayashi, N. Simultaneous Determination of Anthraquinones, Their 8- $\beta$-D-Glucosides, and Sennosides of Rhei rhizoma by Capillary Electrophoresis. Chem. Pharm. Bull. 2005, 53, 573-575.

14. Liu, L.; Fan, L.; Chen, H.; Chen, X.; Hu, Z. Separation and Determination of Four Active Anthraquinones in Chinese Herbal Preparations by Flow Injection-Capillary Electrophoresis. Electrophoresis 2005, 26, $2999-$ 3006.

15. Cai, Z.; Lee, F. S. C.; Wang, X. R.; Yu, W. J. A Capsule Review of Recent Studies on the Application of Mass Spectrometry in the Analysis of Chinese Medicinal Herbs. J. Mass Spectrom. 2002, 37, 1013-1024.

16. He, X. G. On-Line Identification of Phytochemical Constituents in Botanical Extracts by Combined High-Performance Liquid Chromatographic-Diode Array Detection Mass Spectrometric Techniques. J. Chromatogr. 2000, 880, 203-232.

17. Justesen, U. Collision-Induced Fragmentation of Deprotonated Methoxylated Flavonoids, Obtained by Electrospray Ionization Mass Spectrometry. J. Mass Spectrom. 2001, 36, 169-178.

18. Fabre, N.; Rustan, I.; Hoffman, E.; Quetin-Leclercq, J. Determination of Flavone, Flavonol, and Flavanone Aglycones by Negative Ion Liquid Chromatography Electrospray Ion Trap Mass Spectrometry. J. Am. Soc. Mass Spectrom. 2001, 12, 707-715.

19. Ye, M.; Guo, D.; Ye, G.; Huang, C. Analysis of Homoisoflavonoids in Ophiopogon japonicus by HPLC-DAD-ESI-MSn . J. Am. Soc. Mass Spectrom. 2005, 16, 234-243.

20. Ye, M.; Yan, Y.; Guo, D. A. Characterization of Phenolic Compounds in the Chinese Herbal Drug Tu-Si-Zi by Liquid Chromatography Coupled to Electrospray Ionization Mass Spectrometry. Rapid Commun. Mass Spectrom. 2005, 19, 1469-1484.

21. Zeeb, D. J.; Nelson, B. C.; Albert, K.; Dalluge, J. J. Separation and Identification of Twelve Catechins in Tea Using Liquid Chromatography/Atmospheric Pressure Chemical Ionization-Mass Spectrometry. Anal. Chem. 2000, 72, 5020-5026.

22. Seger, C.; Godejohann, M.; Tseng, L. H.; Spraul, M.; Girtler, A.; Sturm, S.; Stuppner, H. LC-DAD-MS/SPE-NMR Hyphenation. A Tool for the Analysis of Pharmaceutically Used Plant Extracts: Identification of Isobaric Iridoid Glycoside Regioisomers from Harpagophytum procumbens. Anal. Chem. 2005, 77, 878-885.

23. Cuyckens, F.; Claeys, M. Mass Spectrometry in the Structural Analysis of Flavonoids. J. Mass Spectrom. 2004, 39, 1-15.

24. Oshio, H.; Imai, S.; Fujioka, S.; Sugawara, T.; Miyamoto, M.; Tsukui, M. Investigation of Rhubarbs. III. New Purgative Constituents, Sennosides E and F. Chem. Pharm. Bull. 1974, 22, 823-831. 
25. Sagara, K.; Oshima, T.; Yoshida, T. Rapid and Simple Determination of Sennoside A and B in Rhei rhizoma by Ion-Pair High-Performance Liquid Chromatography. J. Chromatogr. 1987, 403, 253-261.

26. Sun, S. W.; Yeh, P. C. Analysis of Rhubarb Anthraquinones and Bianthrones by Microemulsion Electrokinetic Chromatography. I. Pharm. Biomed. Anal. 2005, 36, 995-1001.

27. Yang, X.; Zhao, J.; Zhang, Y.; Li, J.; Ma, C.; Hatori, Y.; Nanba, T.Studies on Rhubarb. I. A New Malonylanthraquinone Glycoside from the Rhizomes of Qinling Rhubarb (Rheum qinlingense). Zhongcaoyao 29 2891998293

28. Li, W.; Chan, C. L.; Lueng, H. W. Liquid Chromatography-Atmospheric Pressure Chemical Ionization Mass Spectrometry as a Tool for the Characterization of Anthraquinone Derivatives from Chinese Herbal Medicine. J. Pharm. Pharmacol. 2000, 52, 723-729.

29. Cai, Y.; Sun, M.; Xing, J.; Corke, H. Antioxidant Phenolic Constituents in Roots of Rheum officinale and Rubia cordifolia: Structure-Radical Scavenging Activity Relationships. J. Agric. Food Chem. 2004, 52, 7884-7890.

30. Kerem, Z.; Bilkis, I.; Flaishman, M. A.; Sivan, L. Antioxidant Activity and Inhibition of $\alpha$-Glucosidase by Trans-resveratrol, Piceid, and a Novel Trans-stilbene from the Roots of Israeli Rumex bucephalophorus L. J. Agric. Food Chem. 2006, 54, 1243-1247.
31. Aaviksaar, A.; Haga, M.; Kuzina, K.; Püssa, T.; Raal, A.; Tsoupras, G. Hydroxystilbenes in the Roots of Rheum rhaponticum. Proc. Estonian Acad. Sci. Chem. 2003, 52, 99-107.

32. Jin, W.; Tu, P. F. Preparative Isolation and Purification of Trans-3,5, $4^{\prime}$ Trihydroxystilbene- $4^{\prime}-\mathrm{O}-\beta$-D-Glucopyranoside and $(+)$ Catechin from Rheum tanguticum Maxim. ex Balf Using High-Speed Counter-Current Chromatography by Stepwise Elution and Stepwise Increasing the Flow-Rate of the Mobile Phase. J. Chromatogr. A 2005, 1092, 241-245.

33. Li, Y.; Kim, J.; Li, J.; Liu, F.; Liu, X.; Himmeldirk, K.; Ren, Y.; Wagner, T. E.; Chen, X. Natural Antidiabetic Compound 1,2,3,4,6-Penta-OGalloyl-D-Glucopyranose Binds to Insulin Receptor and Activates Insulin-Mediated Glucose Transport Signaling Pathway. Biochem. Biophys. Res. Commun. 2005, 336, 430-437.

34. Huh, J. E.; Lee, E. O.; Kim, M. S.; Kang, K. S.; Kim, C. H.; Cha, B. C.; Surh, Y. J.; Kim, S. H. Penta-O-galloyl- $\beta$-D-Glucose Suppresses Tumor Growth via Inhibition of Angiogenesis and Stimulation of Apoptosis: Roles of Cyclooxygenase-2 and Mitogen-Activated Protein Kinase Pathways. Carcinogenesis 2005, 26, 1436-1445.

35. Shui, G.; Leong, L. P. Analysis of Polyphenolic Antioxidants in Star Fruit Using Liquid Chromatography and Mass Spectrometry. J. Chromatogr. A 2004, 1022, 67-75. 